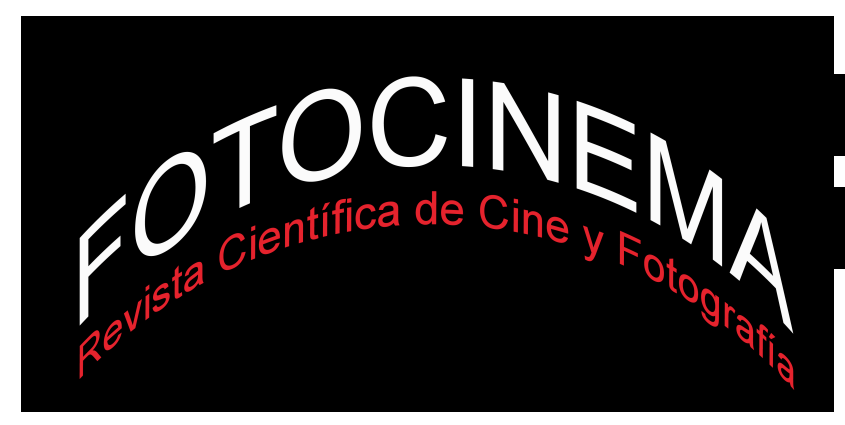

\title{
EL CINE TRAICIONA A LA PINTURA: UN ACERCAMIENTO A LA TEORÍA FÍLMICA FRANCESA DESDE ANDRÉ BAZIN Y JEAN MITRY
}

\section{CINEMA BETRAYS PAINTING: AN APPROACH TO FRENCH FILM THEORY FROM ANDRÉ BAZIN AND JEAN MITRY}

\author{
Santiago López Delacruz \\ Facultad de Información y Comunicación (FIC-UdelaR), Uruguay \\ santiagolopezdelacruz@gmail.com
}

\section{Resumen:}

El presente trabajo indagará en el análisis llevado a cabo por la teoría cinematográfica francesa de mediados del siglo XX acerca de la relación entre el arte pictórico y el arte cinematográfico. Concretamente, se tomarán en cuenta los trabajos realizados por los teóricos André Bazin y Jean Mitry para verificar si el vínculo entre el cine y la pintura esboza anclajes conflictivos en cuanto al problema de la representación. Entendiendo que ambas disciplinas pueden ser tomadas no solo como trascendentes desde un perfil artístico, sino también como generadoras de procesos de significación, es pertinente atender a cuestiones estéticas, lingüísticas y filosóficas para ofrecer un acercamiento a la línea de pensamiento francesa que observa en la relación cine-pintura diversos puntos a discutir. El pensamiento de Bazin, afianzado en una teoría ontológica, y el de Mitry, que expone la condición del cine como arte y lenguaje, resultan claves para analizar el tránsito de la imagen a través de diversas etapas de la historia, desde la representación pictórica a la fílmica, sin olvidar la importancia del surgimiento de la fotografía, en su doble rol de mediadora y disociadora, de ambos periodos de la imagen.

\section{Abstract:}

The present work investigates in the analysis carried out by the French cinematographic theory of the middle of century XX on the relation between the pictorial art and the cinematographic art. Specifically, we take into account the work done by the theorists André Bazin and Jean Mitry to verify if the link between cinema and painting has conflicting anchors on the problem of representation. Understanding that both disciplines can be taken not only as transcendental from an artistic profile, but also as generators of meaning processes, it is important to attend to aesthetic, linguistic and philosophical questions to offer an approach to the French line of thought observed in the relationship film-painting various points to discuss. Bazin's thought, based on an ontological theory, and Mitry's exposition, which exposes the condition of cinema as art and language, are key to analyze the transit of the image through various stages of history, from the pictorial representation to the filmic, without forgetting the importance of the emergence of photography, in its dual role of mediator and dissociator, of both periods of the image.

Palabras clave: estética; André Bazin; lenguaje cinematográfico; teoría del cine; Jean Mitry; pintura.

Keywords: Aesthetic; André Bazin; Film language; Film theory; Jean Mitry; Painting. 
Cómo citar: López Delacruz, S. (2018). El cine traiciona a la pintura: un acercamiento a la teoria fílmica francesa desde André Bazin y Jean Mitry. Fotocinema. Revista científica de cine y fotografía, $\mathrm{n}^{0}$ 16, pp. 79-101.

Disponible: http://www.revistas.uma.es/index.php/fotocinema/

DOI: http://dx.doi.org/10.24310/Fotocinema.2017.voi15

\section{Introducción}

No se puede comprender la relación entre cine y pintura sin dejar de mencionar la relación precedente entre fotografía y pintura. El surgimiento de la fotografía "estaba llamado a interferir de manera notoria la evolución de las artes pictóricas" (Zunzunegui, 2010, p. 133). La fotografía marca, a mediados del siglo XIX, un hiato en la tradición histórica de la pintura, ya que provoca que esta última tensione las formas y maneras de la representación, no simplemente estéticas, sino en relación a la concepción y la esencia de la imagen.

El abordaje de la discusión entre pintura y fotografía está planteado debido al factor determinante de la consolidación de la técnica, ya que mientras el acto de fotografiar se realiza sobre un material ontológicamente transformado, en la pintura reproducir lo real existe a partir de una determinada idea de la visión. Lo fotográfico supone entonces trabajar sobre la realidad utilizando una dimensión visual inédita de la misma. (Catalá, 2011, p. 58).

El advenimiento del dispositivo fotográfico supuso un quiebre en la tradición de representación pictórica. La pintura primero empezó a debatirse consigo misma sobre la estética de la representación, sobre todo después de la crítica hacia la perspectiva albertiana del Quattrocento, a la cual se la denominó como una posibilidad de destrucción del espacio plástico arraigado en la tradición cultural (Francastel, 1984, p. 79). Posteriormente, el hacer pictórico disertó contra la fotografía sobre la esencia de la representación en base a la discusión sobre la técnica y la relevancia artística. Las imágenes producidas por ambos medios iban a ser testigos de un cambio en su forma de ser concebidas, ya que "la fotografía supuso, con su reproducción mecánica de 
las apariencias, un relevo para la pintura en su tarea de testificación del mundo”. (Zunzunegui, 2010, p. 34).

La dicotomía entre imagen fotográfica e imagen pictórica radica en un problema sobre el medio de expresión. ¿Hay especificidad artística en ambas? Si la fotografía es un medio de reproducción con base puramente técnica en donde las imágenes son producidas por el dispositivo-cámara y no por el hombre, ¿qué le queda entonces por hacer al hombre para trabajar artísticamente la realidad? La dualidad sobre el problema de la imagen se vio acentuada por la aparición de una nueva forma de representación de elementos visuales, por un novedoso dispositivo capaz de registrar, producir y significar, las tres acciones, de forma simultánea: el cine.

Desde sus inicios, el cine se vio influido por su relación con otras artes. A través de su Manifiesto de las Siete Artes, el teórico Ricciotto Canudo considera al cine como el arte total, que aúna los logros alcanzados por las otras seis artes categorizadas por Charles Batteux (la literatura, escultura, arquitectura, danza, música y pintura), convirtiéndose en el arte del futuro, la síntesis entre las artes del espacio y las del tiempo (Cabot, 2016, p. 133). De esta manera, lo cinematográfico pareció irse conformando como un arte interdisciplinar, que tomó, moldeó y reconfiguró las artes precedentes para establecerse como una forma de representación que anhelaba buscar su propia especificidad artística.

En la búsqueda que realiza el cine de su propia esencia en el arte, de aquello que le sea exclusivo y propio de su forma, técnica y estética, se vio implicada la tarea de la separación de la obra cinematográfica de otras obras de arte. Desde la primera mitad del siglo XX en adelante, empieza a surgir el debate sobre la especificidad del cine, observándose cuál era el compromiso del cine con las otras artes. Para socavar esta disputa, el papel de la teoría fue fundamental:

La teoría cinematográfica del período mudo se ocupaba, aunque fuese tan solo intuitivamente, de cuestiones que acabarían perpetuándose en el ámbito del cine: ¿el cine es arte o mero registro mecánico de fenómenos visuales? Si es un 
arte, ¿cuáles son sus principales características? ¿En qué difiere de otras artes como la música, la pintura y el teatro? (Stam, 2001, p. 43).

En la etapa primaria del cine, correspondiente al primer cuarto del siglo XX, la teoría cinematográfica elucubraba diversas reflexiones acerca de la condición esencial del aparato cinematográfico, en pos de dos objetivos: transformar al cine en un arte, independiente y heterogéneo, y que esa metamorfosis suponga su alejamiento de las otras artes. En otras palabras, la teoría de la época estaba interesada en demostrar que los elementos específicos que transformaban al cine como arte, eran los mismos que lo hacían separar de las demás disciplinas.

Algunos de los teóricos de la época, tradicionalmente llamados formalistas, incluían a Hugo Münsterberg, que expresaba que la materia prima del cine era la mente y que el filme debía responder a ella mediante recursos psicológicos y estéticos, Rudolf Arnheim, que indicaba la importancia del cine como arte al tratar de alejarse lo más posible de toda representación fiel a la realidad; y Béla Balázs, que proponía que el cine debía poseer su propio lenguaje-forma que finalmente lo aleje de su dependencia de otros artes.

A mediados del siglo XX, uno de los pilares de la exposición teórica sobre cine fue la línea de pensamiento cinematográfico consolidado en Francia. Dos autores, con sus respectivas reflexiones sobre el universo cinematográfico destacaron durante dicho período: el crítico de cine André Bazin y el historiador y teórico Jean Mitry. Cabe señalar que para Casetti (1990, pp. 22-25), el estudio de la teoría cinematográfica se puede dividir mediante los siguientes paradigmas: las teorías ontológicas (se preguntan por la esencia del cine), las teorías metodológicas (abogan por una disciplina científica de estudio) y las teorías de campo (preocupada por el vínculo recíproco entre el cine y lo socio-cultural).

La importancia de la presencia de los dos teóricos mencionados es exclusivamente en base a la categorización realizada por Casetti: André Bazin se enmarca dentro del aspecto ontológico de la teoría y el análisis de filmes, preguntándose sobre qué es el cine desde la reflexión filosófica; Jean Mitry es el autor de transición entre la teoría ontológica y la teoría metodológica, 
puesto que toma elementos de la teoría baziniana, pero incorpora un nuevo nivel de análisis: el relacionado al lenguaje del cine.

Ambos teóricos se colocan desde aristas diferentes para establecer su análisis: mientras que Bazin le da importancia a la realidad desde lo existencial, Mitry agrega el problema de la imagen como objeto de significación. Ante esto, surge la interrogante: ¿de qué forma ha tratado la teoría cinematográfica francesa de mediados del siglo XX la compleja relación entre cine y pintura?

\section{Coordenadas de la representación en el cine y la pintura}

Los conflictos, sean explícitos o tácitos, suscitados entre el arte pictórico y el arte cinematográfico, están sujetos al mismo anclaje de debate que opera de trasfondo sobre la interpretación de la obra de arte: el problema de la representación.

En primera instancia, el concepto de representación va más allá de una definición que implique rasgos relacionados a la sustitución, reproducción o presencia de cualquier especie de "algo". El término "representación" vincula hecho y creación de forma simultánea, esconde tanto a la operación para llevar a cabo la sustitución del referente como el resultado de esa operación, lo que tradicionalmente conocemos como "lo representado". (Casetti \& Di Chio, 1991, p. 121).

Nace una relación recíproca: la del referente, ubicado en la realidad externa a la representación, y la de lo representado, como recorte de aquella realidad en donde el respectivo referente se encontraría. No obstante, la operación se encuentra ante la inevitable paradoja de la presencia de la "cosa representada", ante la huella de un referente qué es y existe en una realidad concreta, y su igual ausencia, en relación a la distancia que expone la imagen como ilusión y espejo de lo real a través de la dimensión plástica.

Zunzunegui (2010, p. 58) plantea que una imagen es imagen de otra cosa y mantienen una relación de representación con su tema respectivo cuando se 
respetan dos condiciones: que la forma autorice el significado con la que se le quiere sustituir, y que el contexto fije dicho significado de forma adecuada.

Lo que se pretende hacer notar son las estrategias de representación de la paradoja presencia-ausencia, para corroborar de qué forma la imagen puede cumplir con su función sustitutiva apelando a diversos recursos, herramientas y estrategias. Surge así una interrogante central: ¿qué estrategias de representación son las que consagran el cine y la pintura para erigirse como objetos de arte y de qué forma son tomadas por Bazin y Mitry a la hora de confrontarlas entre sí?

Para indagar sobre como analizar la representación en el arte pictórico, es necesario comprender el elemento específico de la pintura, a nivel estético, icónico y técnico: la composición. Del mismo modo que la representación es considerada como una operación, la composición es entendida como la manera en la que la forma, el color y el movimiento se combinan en una obra de arte. (Arnheim, 2001, p. 9).

La composición se vuelve el elemento de análisis central de la representación: es el trabajo del artista, en este caso el pintor, que a través de un modo ordenado expone la armonía de las formas para su propia percepción y la de sus espectadores. La representación ocurre en los campos delimitados de la imagen, físicamente traducidos en el marco del cuadro. Dentro del mismo, lo representado se hace presente a través de la diagramación del espacio (profundidad, textura, color, posición y medida) por parte de la condición manual del artista.

Teniendo en cuenta el concepto de composición de la imagen, en principio cabría señalar que el cine también la posee, puesto que, al igual que la pintura, representa en imágenes. Pero para Casetti \& Di Chio (1991, p. 126) en el cine se presentan tres niveles de representación: la puesta en escena, la puesta en cuadro y la puesta en serie. Tanto en la puesta en escena, que tiene que ver con la ordenación de los elementos (objetos, decorados, iluminación e incluso los propios actores) dentro de la imagen, como para la puesta en cuadro, que expresa el encuadre y el punto de vista del realizador, se notan 
claras referencias a la composición pictórica. Sin embargo, el giro lo da el elemento específico del cine: el montaje, sin evidencia en la pintura, ya que articula la relación entre imágenes en base al tiempo y al movimiento de la puesta en serie.

Para el caso de la pintura, el análisis de la representación es la composición de la imagen. En cuanto al cine, la representación se suscita a nivel de la composición de la imagen, por puesta en escena y encuadre, y a nivel de montaje, en la relación de una imagen con otra dentro de la estructura fílmica. En el primer nivel, la teoría de André Bazin cobrará relevancia al proponer una visión existencial de la imagen con los elementos que toma de la realidad, a través de la limitación de la mise-en-scène ${ }^{1}$ y la pantalla. En el segundo nivel, Jean Mitry elaborará su propuesta teórica en búsqueda de un lenguaje cinematográfico afianzado en la estructuración principal de sus procesos de significación: el montaje.

Surge, de una forma más explícita, el problema de la representación fílmica, en donde el gran problema radica en el objeto-pantalla. ¿Qué es lo que se plasma en pantalla? ¿La realidad o su recorte, la convención de lo establecido como lo real? ¿Cuánto hay de ausencia y cuánto de presencia del mundo material en la imagen fílmica?

Es el mismo debate que se generó al respecto de las obras pictóricas. En primera instancia, la pintura venía con el flanco crítico hacia la perspectiva albertiana, o la también llamada perspectiva cónica, término expresado por el arquitecto y escultor Filippo Brunelleschi en la época del Quattrocento, durante los siglos XV y XVI. La humanidad ya no veía con el único punto de vista inamovible propuesto por el Renacimiento, empezando a cuestionarse la forma de representación. La estética basada en la geometrización, la construcción del paralelismo y la condición de un único punto de fuga, que a su vez se expresaba como la construcción más cercana a la óptica del ojo

\footnotetext{
${ }^{1}$ El término mise-en-scène hace referencia al orden espacial en el que los elementos de una película (decorados, objetos de utilería, vestuario, iluminación e incluso los propios intérpretes) se disponen ante la imagen fílmica.
} 
humano, fue puesta en debate por posteriores tradiciones de la historia de la pintura.

Gubern (1996, p. 35) cita el ejemplo de Las meninas (1656), de Diego Velázquez, como el quiebre en la tradición de la perspectiva albertiana: "Las meninas clausuró en 1656 las certezas del dogma geométrico perspectivista, proponiendo un punto de fuga inestable (¿el espejo o la puerta del fondo?) y cuestionando la posición del observador ante la imagen-escena”.

El cuestionamiento en la pintura radica en la interrogante sobre la realidad y la forma pertinente en la que se pueda generar la adecuación de la misma al lienzo. ¿Cuánto hay de realidad en el trazo del pincel? ¿La labor del artista es mimetizar la realidad o establecer un mundo diegético en el marco del cuadro? ¿El cuadro debe basarse en la perspectiva de ilusión geométrica o se está en presencia de un nuevo modo, una nueva óptica, una nueva "ideología" de representación?

\section{La pintura es traicionada, el cine se hace cargo de lo ontológico}

La teoría de André Bazin se basa primordialmente en el carácter ontológico del cine. Surge el cuestionamiento sobre qué es el cine desde dudas esencialmente filosóficas: ¿el arte del cine es el arte del ser? ¿El cine participa de la realidad o la realidad participa del cine? ¿Cuál es el papel del individuo ante la representación ontológica? Para contestar todas estas preguntas, Bazin (1990, p.21) propone el complejo de la momia, que según el autor es inherente al origen de la pintura y la escultura, y que significa escapar a la inexorabilidad del tiempo y vencer a la muerte:

La invención de la fotografía fue un seísmo en todo el sistema de la visualidad moderna, tal como se sensibilizó en la pintura practicada en los últimos cuatro siglos, desde el Renacimiento hasta final del siglo XIX. Aún mayor conmoción fue la que produjo la cinematografía: Unía la congelación del movimiento posibilitada por el avance de la química con las técnicas de sucesión de imágenes que había explotado Eadweard Muybridge, dando 
como resultado un fenómeno nunca experimentado: la posibilidad de generar imágenes en movimiento. (Cabot, 2016, p. 132).

El complejo de la momia implica la obsesión del hombre por volverse inmortal. A lo largo de la humanidad, el ser humano se ha visto envuelto en la necesidad de trascender ontológicamente, de inmortalizar todo aquello qué es, existe y le es propio. La única forma para el hombre de lograrlo es tratar de superar dos factores con los que ha luchado desde su nacimiento: el tiempo y su resultado inmediato: la muerte.

Para tratar de solucionar el problema de la muerte es que surgen las artes. Allí, el ser humano encuentra un salvataje, un punto de fuga para su inmortalidad. El hombre podía morir física pero no espiritualmente, la muerte no podía luchar contra la representación hecha por la escultura o la pintura. Ahora verdaderamente el hombre podía vivir en las esculturas o en los cuadros, y de esa forma tanto su cuerpo como su espíritu iban a quedar inmortalizados, tal y como promulgaba la religión egipcia en su proceso de momificación y conservación de los cuerpos en siglos pasados.

En el caso de la pintura, enmarcada en la representación fiel de la realidad propuesta por el Renacimiento, es en donde surge la ontología de la imagen pictórica, que se propone un propósito mayor: "no se trata ya de la supervivencia del hombre, sino -de una manera más general-, de la creación de un universo ideal en el que la imagen de lo real alcanza un destino temporal autónomo" (Bazin, 1990, p. 24). Lo que significa que, desde la tradición del Quattrocento, la pintura ha tenido una obsesión por representar al mundo a través de su doble; propósito que se verá amenazado por la invención de la fotografía y su posibilidad de reproducción basada en la técnica.

En la teoría de Bazin (1990, p. 24), la fotografía y el cine explican la crisis que la pintura moderna ha tenido desde el siglo XIX. De ser así, ¿cuál es entonces el relevo que la fotografía hace de la pintura? ¿Cuál sería el gran cambio que supone el pasaje de un modo a otro de representación? La respuesta está en un abordaje desde el oficio de la técnica, que no estuvo exenta de gran 
polémica², sobre todo en sus inicios: "la mano contra el espíritu: el Renacimiento, lamentablemente, los había reconciliado, poniendo al pintor casi al nivel del escritor. El captador de sombras va a relanzar, en contra suya, la sempiterna oposición de lo mecánico y de lo liberal”. (Debray, 1994, p. 225).

La pintura iba a ser relevada, no por un nuevo sucesor que evolucionará el espacio plástico, sino por un dispositivo mecánico que iba a trascender la esencia de la representación. Por primera vez, la mano del hombre, del creador, del artista, iba a ser suplantada por la máquina. En la fotografía, no hay posibilidad de mediación entre el hombre y la realidad: todo sucede dentro de la máquina, toda decodificación e interpretación (siempre y cuando se ciña a una mirada antropomórfica de la técnica) pasa por el artefacto, ya no por el trazo del ser humano.

La fotografía sitúa a la representación en una paradoja: la obsesión por momificar la existencia del ser humano ahora es responsabilidad de la objetividad de la técnica. Pero para ello, el ser humano debe dar fuera de la mediación. ¿De qué forma entonces puede existir una presencia de lo ontológico en la imagen fotográfica, basada puramente en la reproducción? $\mathrm{Al}$ respecto se expone una distinción entre la fotografía de arte y la fotografía de reportaje, en donde se deja en claro el matiz ontológico:

La foto de arte desmultiplica la obra única, pero la buena instantánea del fotorreportero es en sí misma única (...) el aparato fotográfico ha reencantado lo acontecido con el documento sensacional. Lo maravilloso maquinista es el scoop. No lo no visto, sino lo jamás visto. El instante que no conocerá una segunda vez. La cara inaccesible de la diva. El gesto imborrable, irrecursable del deportista, del político o del quidam (...) El aura corre como el hurón, del objeto al sujeto. (Debray, 1994, p. 229).

\footnotetext{
${ }^{2}$ Cabe señalar que el invento del daguerrotipo, desarrollado por Louis Daguerre en 1839, es tomado como el primer paso del proceso hacia la fotografía. Definido como una tecnología, supuso la transición de las artes plásticas a las industrias visuales, a tal punto de que es famoso el comentario expuesto por el pintor Paul Delaroche frente al nuevo invento de Daguerre: "A partir de hoy, la pintura ha muerto." (Debray, 1994, p. 225).
} 
De este modo, más allá de la crítica3 que le es hecha a la fotografía por ser engendrada desde un pensamiento para la reproducción, hay un trasfondo que involucra y modifica el proceso del ser en su constitución. La fotografía capta el instante de la vida, el que aconteció en la realidad y se actualiza en la imagen ante cada lectura de su espectador, pasado y presente del ser y el espíritu que perdura en el recorte fotográfico. Pero entonces, ¿qué sucede con el cine, el más inmediato predecesor de la fotografía? Bazin (1990, p. 29) responde que el cine termina siendo la consolidación de la objetividad fotográfica (contraria a la subjetividad pictórica), porque le añade el componente tiempo 4 a través del movimiento de la imagen, momificando el cambio y generando que la imagen de la realidad sea también la del principio y fin de la condición espacio-temporal.

Para lograr la objetividad y la trascendencia ontológica, el cine debe enfrentarse a la pintura, puesto que la fotografía ha liberado a esta última de la obsesión de representar la realidad. Ante esto, Bazin (1990, p. 211) procede a un estudio de análisis cinematográfico de diversas obras 5 que tienen relación con la pintura, sea biográfica o estéticamente, sentenciando que el cine traiciona a la pintura, y que esa traición ocurre en todos los niveles de representación.

Lo interesante en el autor, no es el análisis que realiza de la pintura a través de las películas que tratan la problemática de la pintura, sino la forma en la que evidencia las dicotomías del lenguaje pictórico y fílmico, proclamando el problema de la representación artística como un debate tanto a nivel

\footnotetext{
${ }^{3} \mathrm{Al}$ respecto, siempre es pertinente tener en cuenta el ensayo La obra de arte en la era de la reproductibilidad técnica, escrito por Walter Benjamin en 1936, en donde el autor reflexiona sobre la pérdida del aura (la autenticidad, el carácter de testimonio histórico, la permanencia material) de la obra de arte debido a la reproducción, que produce un trastorno en la tradición histórico-crítica del objeto de arte al masificarlo y multiplicarlo en aras de la copia y la imitación (2003, pp. 44-45).

${ }^{4}$ Es pertinente mencionar el trabajo que realiza Gilles Deleuze (París, 1925-1995) sobre las categorías de imagen-tiempo e imagen-movimiento, conceptos aplicados a la construcción de un estudio fenomenológico del cine. A su vez, Bazin es nombrado por Deleuze repetidas veces a lo largo de sus obras, ya que ambos consideraban a la fotografía como un objeto de pensamiento privilegiado (León, 2016, p. 191), infiriéndose una línea de análisis continúa entre los dos autores.

5 Entre las películas que Bazin toma para su análisis se incluyen Van Gogh (Alain Resnais, 1948) y El misterio de Picasso (Le Mystère Picasso, H.G. Clouzot, 1956).
} 
filosófico como estético. Para ello, explica que la pantalla destruye radicalmente el espacio pictórico (Bazin, 1990, p. 212), por lo que su posición acerca del conflicto entre cine y pintura va a derivar en dos factores de relativa congruencia: el problema del marco en la pintura y el problema de la pantalla en el cine.

El análisis de Bazin radica en el hecho de como la imagen es tratada por su soporte: la pantalla; como es ella la que le pone límites, pero también la que diferencia al cine de otras artes. Posiblemente, el gran triunfo del cine con el espectador no sea por el uso de la imagen, sino por el poder de los marcos, bordes y fronteras de la pantalla. Es la misma situación que planteaba Barthes (1986, p. 353) al catalogar a la imagen fílmica como una trampa, en donde las escenas debían ser mimadas por la pantalla y en último caso, el espectador construía su imaginario a partir de un proceso de identificación con el espejo de la pantalla. Por lo tanto, las estrategias de las que se vale el cine para ejercer su "traición" hacia la pintura, obrará en un trabajo desde la representación en pantalla a tres niveles: el montaje, la plástica de la imagen y los límites del encuadre.

A través del montaje, el cine reconfigura el espacio perceptivo del espectador frente a la obra. En la pintura, el único montaje existente es el que sucede dentro del cuadro y en profundidad, dado por la propia especificidad pictórica de la representación, a través del ordenamiento de los diversos elementos que componen la plástica de la imagen. Bazin (1990, p.212) expresa que el montaje fílmico reconstruye una unidad temporal horizontal, disímil a la temporalidad del cuadro, la cual se desarrolla geológicamente en profundidad y provoca una situación indefinible ante la continuidad geométrica, entre el cuadro y la pared, entre la pintura y la realidad.

El principio baziniano intenta dejar explícita la traición de lo fílmico hacia lo pictórico no solo a través de lo que sucede dentro de la pantalla, sino también lo que está fuera de ella, por encima de la frontera de sus bordes. Así, la reflexión de Barthes sobre la capacidad que tiene la pantalla para concentrar la atención del espectador es la que se deja traslucir en el concepto de que, 
finalmente, es la propia pantalla la que pone los límites con la realidad, con el espectador y con la imagen fílmica.

Bazin (1990, p. 213) añade: "los límites de la pantalla no son, como el vocabulario técnico podría a veces hacer creer, el marco de la imagen, sino una mirilla que deja al descubierto una parte de la realidad”. Allí realiza una distinción entre la pintura y el cine: el marco de la pintura actúa en base a la profundidad como una fuerza centrípeta, el borde de la pantalla actúa en base a la extensión de lo que está por fuera con una fuerza centrífuga. Tratar al cine como mirilla es reconocer que hay un mundo-mas-allá de esa cerradura convertida en pantalla, y que innegablemente la ausencia de lo que queda por fuera sopesara la presencia de lo que se está mostrando.

Cabe señalar que lo centrípeto está relacionado con el concepto de la geometría de la profundidad del espacio pictórico, lugar de espacio y reflexión donde aparece el reconocimiento de las formas (Zunzunegui, 2010, p. 119); lo centrípeto en la pintura es un proceso desde y hacia dentro de la imagen. Para Bazin en cambio, ante el espacio cinematográfico solo se pueden extrapolar los procesos: el marco ya no es limite sino frontera, lugar de encuentro de la presencia de lo representado y la ausencia material de su referente; la acción centrífuga genera un proceso continuo de ida y vuelta al espacio de la imagen fílmica, diálogo constante entre el referente ausente y su trazo de representación, evidenciado en pantalla.

La teoría de André Bazin plantea una diferencia entre la pintura y el cine a través de las diversas especificidades de este último: el uso del montaje, la cualidad del movimiento y la condición de lo ilimitado en el espacio fílmico perturban la representación del espacio pictórico. Y lo hace no solo desde la plástica de la imagen, sino también desde la capacidad ontológica del dispositivo cinematográfico de interferir objetivamente en el proceso del ser y la realidad material.

En la película El río (Le fleuve, Jean Renoir, 1951) se podría haber observado una clara influencia en Renoir de la tradición pictórica de su padre ${ }^{6}$, desde

${ }^{6}$ Pierre-Auguste Renoir (Francia, 1841-1919), pintor impresionista. 
una perspectiva puramente estética. Sin embargo, el propio Bazin responde al respecto de la película que el cambio de medio de expresión (del lienzo del cuadro pictórico al marco de la pantalla cinematográfica) es el que condena cualquier tipo de diálogo entre cine y pintura: la pintura representa la realidad de forma abstracta, mientras que el cine, a la vez de la condición abstracta, también expone una perspectiva existencial.

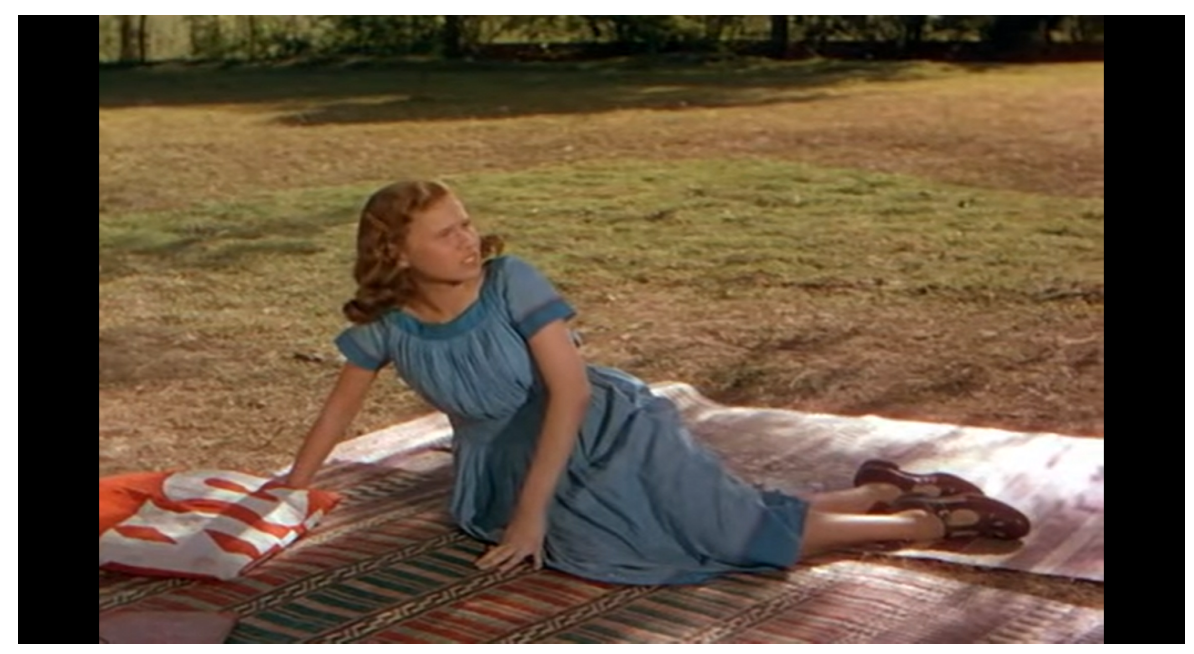

F1. El río.

La fuerza centrípeta de la imagen pictórica conlleva a la ilusión de profundidad acotada a lo espacial: nada puede haber más allá del cuadro, porque la realidad ya fue abstraída en base a la composición, la linealidad y los colores. En el cine, en cambio, siempre va a haber información más allá del marco de la pantalla: hay un recorte y un encuadre que delimitan lo fílmico y la realidad, pero que a su vez actúan como frontera entre lo representado y lo que está por fuera.

En el encuadre de la película de Renoir, difícilmente se pueda separar la figura de Harriet de su campo espacial, no por una simple elección fotográfica o de diseño de producción, sino por la no disolución del campo fílmico del campo de lo real. Los límites y recortes parecen cruzarse de forma perpetua en la extensión de la imagen fílmica más allá del cuadro: el raccord de la mirada de Harriet hacia algo fuera del cuadro implica dicha expansión, sumado a la profundidad de los elementos del "mundo real” (los árboles, la colina, el pasto, etc.) y la iluminación (natural, de un sol que no figura en 
cuadro pero que se hace presente en las luces y sombras del mismo). Es decir, la puesta en escena de la imagen fílmica genera un continuo diálogo entre el interior y el exterior del encuadre cinematográfico, entre la presencia y ausencia de los elementos representados, entre los límites del campo ficcional y lo ilimitado de la condición ontológica de la realidad.

La distinción entre cine y pintura parece clara en Bazin, y en parte la fotografía es la gran aliada en explicitar dicha dicotomía. Tomando en cuenta los elementos que el autor evidencia de la acción cinematográfica y el recorrido turbulento que tuvo la tradición clásica de la pintura desde el siglo XIX, se puede identificar que el debate ya no forma parte del problema de la representación de manera exclusiva. Ahora, las diferencias parecen surgir en un nuevo nivel, y con ello un nuevo campo de análisis se despliega para acentuar la disputa: el concerniente al paradigma del lenguaje.

\section{4. ¿Un lenguaje para el arte?}

Con la entrada en escena de Jean Mitry, la reflexión teórica sobre el cine empieza a subordinar el cariz filosófico de la teoría de André Bazin para hacer hincapié en cuestiones relacionadas con el aspecto lingüístico, aunque en un principio se continúe el perfil ontológico de análisis del cine al definirse al arte como "la expresión del sentimiento absoluto que el hombre lleva en sí, y que busca en los datos del mundo sensible, más allá de esos datos mismos" (Mitry, 1986, p. 7).

Desde un principio, Mitry pasa a considerar al cine como arte, tal y como Canudo lo hizo a principios del siglo XX y en la tradición posterior de los teóricos formalistas. Se puede develar en la ambición artística tres factores simultáneos: un fenómeno social una necesidad psíquica y una realidad estética (Mitry, 1986, p. 10); en la triada de dichos factores el cine se ubica de manera confortable, puesto que como expresaba Bazin, el cine toma de la realidad los diversos factores sociales para consagrarse en las necesidades existenciales del individuo, a la vez que se conforma como un dispositivo estético de representación. 
$\mathrm{Al}$ respecto de la pintura, se debe volver a comprender que se erige primero como representación y posteriormente como narrativa, al igual que las demás artes. Pero la gran virtud de la pintura, que es el investirse como medio de expresión del espacio en cuanto al uso de las formas, el ser-narrativo, el transformarse en un relato, el autenticarse como representación implica también poseer un manejo sobre el tiempo, algo no evidenciable en el arte pictórico.

En sintonía con el pensamiento baziniano, Mitry aboga por la condición "tiempo" para diferenciar al cine de cualquier otra arte. El tiempo es la condición primogénita, la que permite la articulación de planos, encuadres y puntos de vista, la que brinda la oportunidad a la imagen cinematográfica de poseer algo que no está presente en la pintura: el ritmo.

Al hablar de ritmo de la imagen, no se debe confundir con velocidad, dinámica o aceleración narrativa. En el campo de la imagen, el ritmo visual viene limitado por el plano del cuadro, se apoya en la duración y yuxtaposición de los planos en el montaje y depende de las variaciones visuales que se producen en el cuadro de la pantalla, por unidad de tiempo (Palau Pellicer, 2012). Por lo tanto, el análisis de Mitry va en función de la relación existente en la travesía tanto de la imagen entre cuadros (composición) como de la imagen entre imágenes (montaje), y allí es en donde distingue lo fílmico, como arte del tiempo, de lo pictórico, como arte del espacio.

Por otro lado, Mitry (1986, p. 44-45) define a la pintura como un medio de expresión. No puede expresar ideas, puesto que se estaría ante un oxímoron: toda idea se funda en procesos de significación, articuladas en un lenguaje. Por lo tanto, lo pictórico es el arte de los sentimientos, de las emociones, tal y como lo es la danza, la arquitectura o la música. Un cuadro transmite emociones, pero no las puede traducir, ni comunicar, ni convencerlas de volverlas significación, debido a que las artes de la expresión no se fundan en un lenguaje; si lo hicieran, dejarían lo expresivo por lo comunicativo, en efecto dejarían de ser un arte. 
La obra pictórica para Mitry no posee un lenguaje, sino que se conforma como representación expresiva. Sin embargo, en cuanto a la obra cinematográfica la situación es distinta, ya que la representación en el cine es semejante a la literatura. Esta última utiliza el lenguaje del verbo en la poesía o la novela como formas estéticas, accediendo primero a la idea, luego a la emoción, lo cual lleva a definir al cine como una forma estética (tal como la literatura), que utiliza la imagen qué es (en sí misma y por sí misma) un medio de expresión cuya sucesión (es decir la organización lógica y dialéctica) es un lenguaje (Mitry, 1986, p. 45).

Si para Mitry el cine a la vez de ser representación artística supone ser un lenguaje, entonces también se lo podría tomar como una escritura que fija un lenguaje determinado a través de determinadas formas simbólicas, a través del verbo y la palabra, en donde la imagen es (como arte) y es imagen de algo (desde el lenguaje), sin posibilidad de abstracción como en la pintura, puesta la noción, también vista en Bazin, de la reproducción de lo real concreto.

En cierto modo, la imagen en la pintura desaparecería detrás de su propia representación, debido a su proceso de abstracción, mientras que en el cine la representación se asemeja siempre a lo representado, por su valor reproductivo y su relación inter-icónica:

Ello implica que la imagen no está cargada de sentido sino en relación con un conjunto de hechos en los que se encuentra implicada. Es el montaje interior o exterior al plano- el qué, a través de la yuxtaposición, hace que las imágenes se comporten como signos connotando un significado ajeno a ellas mismas. (Zunzunegui, 2010, p. 178).

El doble significado del conjunto de imágenes en un filme, en contraposición a la significación unívoca en la pintura, llevará a Mitry a afirmar que la imagen cinematográfica, entendida como signo, es a la vez un símbolo, en el sentido lingüístico, y un analogón, en el sentido psicológico (Mitry, 1986, p. 132).

La imagen fílmica, tal y como lo habían expresado Casetti \& Di Chio, posee tres niveles de representación. Los dos primeros corresponden a la 
composición (la puesta en escena y la puesta en cuadro), mientras que el tercer nivel corresponde a la puesta en serie, que nace a través del montaje. La puesta en serie expone la relación que una imagen posee con una imagen antecesora, de la cual se vuelve víctima, y su consiguiente que tomará el relevo, de la cual asume el rol de testigo. El montaje consignará a este proceso, junto a la puesta en escena y la puesta en cuadro, las diversas significaciones para tratar de estructurar la representación.

Mitry expresará que la imagen se vuelve símbolo cuando forma parte de una cadena significante con otras imágenes dentro de una estructura narrativa con base en el montaje. De esta forma, la imagen significa desde el punto de vista lingüístico porque, dentro de una estructura (el lenguaje cinematográfico) genera relaciones de significado con otras imágenes.

En Django desencadenado (Django unchained, Quentin Tarantino, 2012), las imágenes funcionan a nivel simbólico en la secuencia del tiroteo entre King Schultz, personaje interpretado por Christoph Waltz, y Calvin Candie, interpretado por Leonardo DiCaprio. En la escena de la muerte de Candie, se observa la construcción simbólica de la imagen fílmica por medio del montaje: la secuencia se construye de tres planos que significan, por sí solos, “saludo” (F2), “disparo" (F3) y "herida” (F4).
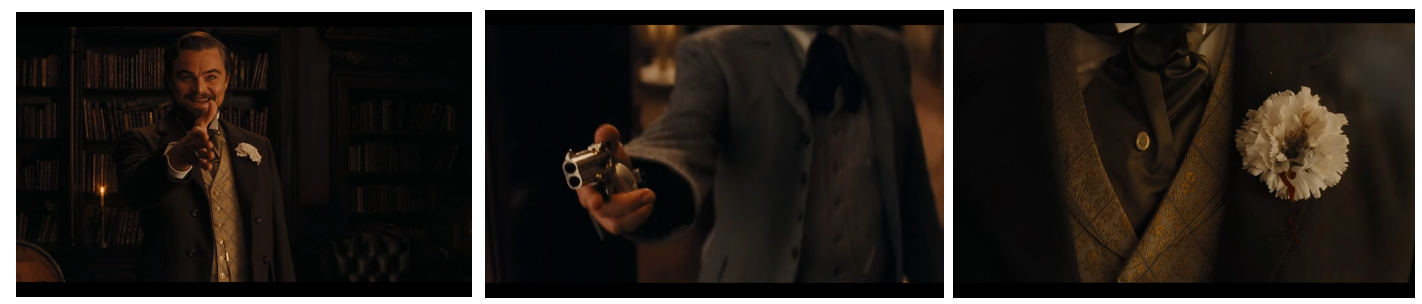

F2: Candie espera el saludo. F3: Schultz se acerca y dispara. F4: Candie es herido de muerte.

Dentro de la articulación estructural narrativa, sin embargo, lo que se forma es un nuevo nivel de representación: una secuencia que se podría denominar "King Schultz hiere de muerte a Calvin Candie", nacida de la relación simbólica entre sus tres imágenes, dentro de una mayor estructuración lingüística basada en lo contiguo.

El significado original de las imágenes por separado (tres planos), al momento de entrar en relación recíproca debido al montaje, construyen una 
nueva instancia de significación más compleja (secuencia). El plano con significado "disparo", por ejemplo, pasa a tener un sentido que ya no le es propio, sino que es dado en base a su relación, su puesta en serie, con otros planos, que le otorgan un nuevo significado: el "disparo" no es solo un disparo, sino que es un disparo que proviene del arma de Schultz, que es utilizada para ejecutar a Candie. La secuencia articula significados según la contigüidad del montaje, dando un nuevo hándicap simbólico a las imágenes que lo componen. Ese es el valor de la imagen como símbolo dentro del lenguaje cinematográfico.

En el caso del concepto de analogón, la imagen permite convivir tanto a la realidad como a su representación dentro de los parámetros, espaciales y temporales, del marco fílmico, exponiendo una polisemia de significaciones que hasta ahora ningún arte había podido recoger. La imagen en movimiento puede ofrecer un registro de determinado objeto, persona o lugar, al mismo tiempo que ese registro se torna representación. La imagen fílmica es análoga de la realidad, puesto que permite generar un diálogo entre referente y representación.

En La pasión de Juana de Arco (The passion of Jeanne d'Arc, Carl Theodor Dreyer, 1928) se puede observar como se presenta la analogía entre realidad y representación a través del uso de imágenes. La aparición de una cruz (F5) en el momento de la procesión de Juana, personaje interpretado por María Falconetti, establece una polisemia de la representación propia del aspecto analógico del cine.

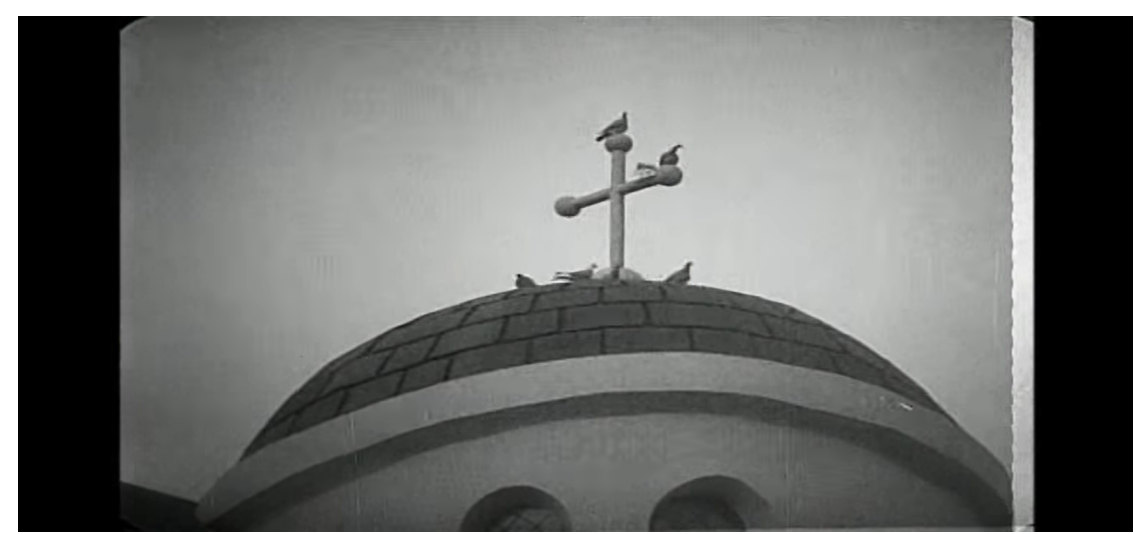

F5. La pasión de Juana de Arco. 
La imagen fílmica de la cruz remite a un ideal, a un arquetipo del objeto-cruz, que se encuentra presente en la realidad por fuera al marco cinematográfico, pero que a la vez se trata del mismo objeto que aparece en el filme. Dentro de la estructura narrativa, formada a través del guión y del montaje, el objetocruz pasará a tener su propia significación (el via crucis de Juana, el silencio de la Iglesia, la condición de lo santificado en oposición a lo maldito), alejada de las convenciones tradicionales que remiten al objeto-cruz en la realidad (cristianismo, religión, santificación, Jesucristo), pero sin dejar de perder su concepto y su definición.

La situación análoga permite que cohabite tanto la imagen de un objeto (su representación en el mundo) como el propio objeto concreto y real (el objeto como parte de un mundo por fuera del marco). En el filme de Dreyer, la recepción que tendrá el espectador continuamente fluctuará entre el simbolismo fílmico del conflicto (el castigo de Juana) y la connotación de la condición de realidad (la Iglesia católica y el cristianismo en tanto institución), dando múltiples sentidos al horizonte de expectativas receptivo. De lo contrario no habría un modelo de relaciones que vincule al objeto con su modelo perceptual para la conformación del signo icónico, en base a operaciones mentales de reconocimiento de la imagen (de allí la condición psicológica de lo análogo). (Eco, 1986, p. 181).

Si se considera a la imagen fílmica como símbolo y analogón, se hace presente una traición a la representación pictórica. La imagen en la pintura se somete al espacio y su profundidad, mientras que la imagen en el cine apuesta tanto por su relación con otras imágenes, como por lo que está más allá de las fronteras de la pantalla:

La imagen está entonces fundamentalmente vinculada a su marco. Todas las significaciones plásticas dependen de el. Y, por tanto, la pantalla aparece como una ventana abierta al mundo. La frontera que limita lo real representado solo pertenece a esta ventana. El mundo continúa de un lado y del otro. (Mitry, 1991, p. 62).

La reflexión de Mitry, muy en línea con el pensamiento de Bazin sobre los límites de la pantalla en base al borde y al marco fílmico-espacial, ofrece un 
nuevo cariz al conflicto entre cine y pintura. Esta última, sin dejar de ser arte, queda ligada a su condición de representación abstracta del mundo. El cine, en cambio, se afianza como arte, en el sentido de que provoca emociones, pero le añade la regulación de una estructura que lo convierte en lenguaje al traducir las emociones en ideas de significación, lo que permite establecer una relación con el mundo mas allá de la representación.

\section{Conclusiones}

A lo largo de la historia de la imagen, tanto la pintura como la fotografía y el cine han establecido diversos parámetros de reflexión en cuanto a los modos de representación de lo visual. Si bien entre sí han ido influenciándose a lo largo de los años, son notorias las diferencias desde lo estético, lo lingüístico y lo filosófico.

Las teorías de André Bazin y Jean Mitry son pertinentes, en primera instancia para observar el panorama de pensamiento de mediados del siglo XX en relación al análisis cinematográfico y las otras artes. En segundo lugar, son el apoyo fundamental para observar de qué forma el cine se fue separando de la pintura, en tanto arte y representación, desde procedimientos puramente técnicos hasta labores, específicamente estéticas, relacionadas a la imagen.

En lo que refiere a la pintura, toda la tradición comenzada desde el Renacimiento hasta los cambios en los modelos pictóricos de representación cercanos al siglo XX fomentaron una nueva forma de mirar el arte, un margen de maniobra al momento de considerar perspectivas heterogéneas de interpretación de las obras. En el caso del cine, es innegable que toma elementos de la pintura, de la fotografía y de demás artes para establecerse como un referente artístico singular, pero también la exploración en el uso del lenguaje (sobre todo, gracias al montaje) permitió que finalmente se emancipara en su búsqueda de especificidad artística.

Más allá de la pertinencia de los autores, igualmente se deben tener en cuenta las limitaciones de sus estudios. Para el caso de Bazin, su posición 
ontológica puede tildarse de idealista y más centrada en lo filosófico que en lo especificamente fílmico, sobre todo desde la perspectiva de la semiótica y del estructuralismo (con autores como Christian Metz a la cabeza) que dominó la teoría fílmica francesa durante los años sesenta. En cuanto a Jean Mitry, su figura de pionero en los aspectos concernientes a una lingüística del cine son la principal crítica realizada por las teorías de campo, interesadas no tanto en la relación simbólica y análoga que existe en pantalla sino en la reflexión sobre la influencia de la sociedad, lo cultural y el imaginario (y esto también incluye la reflexión sobre las artes en general) dentro de la cuestión cinematográfica, algo a lo que la recien naciente corriente lingüística no dio pie en sus inicios.

Pero, concluyendo, las reflexiones de Bazin y Mitry permiten observar, comparar y diferenciar con una analítica meticulosa el conflicto entre el cine y la pintura. Sumado a ellos, estudios más recientes como el de Jacques Aumont en su obra El ojo interminable, que invita a pensar que la relacion cine-pintura es en realidad un falso encuentro de problemáticas compartidas, no hacen más que proponer un rico análisis desde amplios campos de estudio, no solo en el afan de subrayar contrastes, sino también por el hecho de ofrecer lúcidos pensamientos sobre la teoría del cine y su relación con otras artes.

\section{Referencias bibliográficas}

Arnheim, R. (2001). El poder del centro. Estudio sobre la composición de las artes visuales. Madrid: Ediciones Akal.

Aumont, J. (1997). El ojo interminable. Cine y pintura. Barcelona: Paidós Ibérica.

Barthes, R. (1986). Lo obvio y lo obtuso. Barcelona: Paidós Comunicación.

Bazin, A. (1990). ¿Qué es el Cine? Madrid: Ediciones Rialp.

Benjamin, W. (2003). La obra de arte en la era de la reproductibilidad técnica. Ciudad de México: Editorial Itaca.

Cabot, M. (2016). La crítica de Adorno a la cultura de masas. Constelaciones. Revista de Teoría Crítica, 3, 130-147.

Casetti, F. (2005). Teorías del cine. Madrid: Cátedra. 
Casetti, F. y Di Chio, F. (1991). Como analizar un film. Madrid: Paidós Ibérica.

Catalá, J. M. (2011). Reflujos de lo visible. La expansión post-fotográfica del documental. adComunica, (2), 43-62.

Debray, R. (1994). Vida y muerte de la imagen. Barcelona: Paidós Comunicación.

Eco, U. (1986). La estructura ausente. Introducción a la semiótica. Barcelona: Editorial Lumen.

Francastel, P. (1984). Pintura y sociedad. Madrid: Ensayos Arte Cátedra.

Gubern, R. (1996). Del bisonte a la realidad virtual. Barcelona: Anagrama.

León, A. (2016). De la imagen-transparente a la imagen-opaca. Hacia una taxonomía de la imagen fotográfica a partir de la filosofía de Gilles

Deleuze. Estudios de Filosofía, 14, 188-204.

Mitry, J. (1986). Estética y psicología del cine. 1. Las estructuras. Madrid: Siglo XXI Editores.

Mitry, J. (1991). La semiología, en tela de juicio. Madrid: Ediciones Akal.

Palau Pellicer, P. (2012). Ritmo y movimiento en el discurso audiovisual. En Actas del Congreso Iberoamericano de las Lenguas en la Educación (p. 359). Ministerio de Educación.

Stam, R. (2001). Teorías del cine. Barcelona: Paidós Ibérica.

Zunzunegui, S. (2010). Pensar la imagen. Madrid: Cátedra. 